\title{
Low potato yields in Kenya: do conventional input innovations account for the yields disparity?
}

Joseph Gichuru Wang'ombe ${ }^{1,2^{*}}$ and Meine Pieter van Dijk ${ }^{1,3}$

\begin{abstract}
Background: Potato yields in Kenya are less than half the amount obtained by some developed countries. Despite more acreage being dedicated to the crop, annual production has not improved. Kenya's low yields have been blamed on a failure to use clean seeds, fertilizers, fungicides and irrigation. The article examines the impact of adopting these innovations on enhancements of yields.

Results: The regression coefficients indicate that clean seeds have the greatest impact followed by irrigation, fungicides and fertilizers. However, clean seeds have the lowest adoption rate, with only $4.5 \%$ of the respondent sample using such seeds. Irrigation adoption was also low at $23 \%$ but there is widespread usage of fungicides and fertilizers at $92 \%$ and $96 \%$ respectively. Adoption of the four innovations more than doubled the yields but the absolute amount remained less than $50 \%$ of the 40 tons per hectare obtained by the leading world producers. The less than optimal gains can be attributed to the nonlinear relationships of the variables, which indicate the importance of more precise, proper application of inputs in order to obtain higher yields. Linear regression could only explain $10 \%$ of the variation but nonlinear regression improved $\mathrm{R}$ squared to $80 \%$. The unexplained variables accounting for 20\% appear to be essential for a further enhancement of yields, given the big difference between those currently achieved in Kenya and those in developed countries.

Conclusions: Whereas adoption of the inputs is important, there is a need to use precise, recommended application regimes in order to obtain better potato yields. Training, in the form of visits by innovation propagation agents, are shown to improve adoption rates although only about half (55\%) of farmers reported receiving such visits in the preceding three years. This points to a need for the Ministry of Agriculture to lead in increasing the coverage of such visits. Taken together, the four innovations account for only a fraction of the yield variances highlighting the need for further research to identify other determinants of Kenya's low potato production.
\end{abstract}

Keywords: Potatoes, Innovation, Clean seeds, Fertilizers, Fungicides, Irrigation, Yields

\section{Background}

The most consumed food crop in the world is rice, followed by wheat, potatoes and maize in that order [1]. In Kenya, the potato is the second most important food crop after maize, which contributes $32 \%$ of overall dietary energy consumption and $68 \%$ of energy consumption from cereals [2]. The recurrent episodes of famine in periods of drought in recent years, coupled with Kenya's reliance on maize imports to meet its domestic needs suggest that the country has not thus far succeeded in

\footnotetext{
* Correspondence: gichuruwke@yahoo.com

'Maastricht School of Management, Maastricht, Netherlands

${ }^{2}$ African Population \& Health Research Center, P.O. Box 10787, Nairobi 00100, Kenya

Full list of author information is available at the end of the article
}

realizing successful food security strategies. Indeed, contrary to other African countries, for example, Malawi, which have significantly reduced their dependence on cereal imports over the few years, in Kenya it has risen from $20.7 \%$ in 2000 to 2004 , to $36.1 \%$ in 2007 to 2009 [3].

The potato has a demonstrated capacity to feed large populations. Nunn and Quin [4] showed how population and urbanization in Europe and America increased sharply during the eighteenth and nineteenth century following the introduction of the potato as a new food crop. The potato provides more food per hectare than other staples, given its short time to mature (80 to 120 days), which allows two crops per year. Now consumed in most regions of Kenya, the potato deserves consideration, therefore, as a potential focal crop in the

\section{Biomed Central}


country's quest to attain food security. This would call for an enhancement of the potato sector, which is currently classified under 'orphan crops' by the Kenyan Ministry of Agriculture due to its relatively low level of development.

Kenya's potato yields have remained low even as more land is devoted to the crop. This contrasts with the experience of other regions that have experienced the green revolution. Between 1966 and 1980, the acreage under potatoes in North America and Western Europe decreased annually by more than $2 \%$ but yields increased by almost $1 \%$ [5]. In Asia, the acreage increased by about $7 \%$ in the same period and was accompanied by annual yield growth of $2 \%$. In Africa, however, despite a $4 \%$ rise in potato-farmed land, yields remained constant in the same period.

Indeed, yields in the continent are remarkably low at less than 20 tons per hectare for Africa compared to over 40 tons for developed regions like North America (Table 1). This suggests that there is an immense potential for improvement of potato yields in Africa. A set of 'green revolution' innovations that can lead to increased potato yields - clean seeds, fertilizers, chemicals and irrigation are well known and considerable debate has focused on approaches to enhancing their rate of adoption. However, there has been virtually no formal evaluation of the outcomes of their use. This paper assesses the relative impacts of the adoption of clean seeds, fertilizers, fungicides and irrigation on potato yields in Kenya.

\section{Theoretical framework}

Increased productivity for sub-Saharan Africa and Kenya in particular is only going to be obtained through the adoption of innovative approaches. An innovation has been defined as a new product, new technique, new practice or a new idea [6].

We look at key demand and supply factors contributing to the low level of adoption of conventional input innovations as well as their impact once used, as we seek to examine to what extent a greater adoption of such measures would significantly improve potato yields in Kenya. Existing literature on demand factors typically focuses on individual characteristics. Studies have shown, for example, that a younger age and better education of a household head, as well as a larger farm size are associated with a higher likelihood of adopting innovations $[7,8]$. Rogers [7], moreover, suggests that farmers with contacts outside the local community are more likely to embrace new techniques than those embedded in a traditional lifestyle, while Unwin [8] finds people who have been farmers all their lives to be more likely to adopt innovations.

Available research on the supply-side factors shaping the uptake of innovations considers the extent to, and ways in which an innovation is made available to potential users. The innovation is usually availed by institutions and groups outside the farming community. Constraints supply or supply constraints are viewed as being established and controlled mainly by government and private institutions [6].

Ruttan [9] has drawn several generalizations from literature on green revolution. Notwithstanding exceptions due to environmental differences, these include: (1) that new high yielding varieties (HYVs) were adopted at exceptionally rapid rates in those areas where they were

Table 1 Potato production, by region, 2009 and 2010

\begin{tabular}{|c|c|c|c|c|c|c|}
\hline \multirow[b]{2}{*}{ Country/region } & \multicolumn{3}{|c|}{2009} & \multicolumn{3}{|c|}{2010} \\
\hline & Production (tons) & Area (Ha) & Yield/Ha & Production (tons) & Area (Ha) & Yield/Ha \\
\hline Kenya* & $2,299,090$ & 120,246 & 19.12 & $2,725,940$ & 121,542 & 22.43 \\
\hline Uganda & 689,000 & 101,000 & 6.82 & 695,000 & 102,000 & 6.81 \\
\hline Tanzania & 860,980 & 195,690 & 4.40 & $1,472,560$ & 172,970 & 8.51 \\
\hline Eastern Africa & $9,414,400$ & 866,491 & 10.86 & $11,403,695$ & 912,817 & 12.49 \\
\hline Malawi & $3,427,660$ & 161,923 & 21.17 & $3,673,540$ & 160,600 & 22.87 \\
\hline South Africa & $1,866,580$ & 55,000 & 33.94 & $2,090,210$ & 62,200 & 33.60 \\
\hline North Africa & $8,446,031$ & 376,750 & 22.42 & $9,522,840$ & 386,350 & 24.65 \\
\hline Africa & $22,047,635$ & $1,691,139$ & 13.04 & $25,378,948$ & $1,827,282$ & 13.89 \\
\hline Asia & $145,841,189$ & $9,031,772$ & 16.15 & $159,055,291$ & $9,193,486$ & 17.30 \\
\hline European Union & $62,694,978$ & $2,087,172$ & 30.04 & $57,485,831$ & $2,018,117$ & 28.48 \\
\hline South America & $13,880,831$ & 874,378 & 15.88 & $14,475,788$ & 942,423 & 15.36 \\
\hline USA & $19,622,500$ & 422,492 & 46.44 & $18,337,500$ & 407,923 & 44.95 \\
\hline North America & $24,151,275$ & 569,249 & 42.43 & $22,760,270$ & 547,868 & 41.54 \\
\hline WORLD & $329,581,307$ & $18,651,838$ & 17.67 & $324,420,782$ & $18,653,007$ & 17.39 \\
\hline
\end{tabular}

*FAO yield estimates from 1999 to 2004 were all less than 10 tons per hectare and it is not clear what changed from 2005 onwards when estimates were more than doubled. Source: Food and Agriculture Organization (FAO), accessed April 2013. 
technically and economically superior to local varieties. This illustrates that technical and economical evaluations have an impact on adoption; (2) neither farm size nor tenure has been a serious constraint to the adoption of HYVs of grain. While smaller farmers and tenants tended to lag behind larger farmers in the early years following their introduction, these lags typically disappeared within a few years; (3) the introduction of HYVs has resulted in an increase in the demand for labor; and (4) land owners have gained relative to tenants.

The adoption of an innovation is primarily the outcome of a learning and communication process. This implies that there are factors related to the effective flow of information and the characteristics of information flows, information reception and resistance to adoption. Adoption will depend on an individual's general propensity to adopt innovation or his innovativeness [7]. It will also depend on the congruence between the innovation and the social, economic and psychological characteristics of the potential adopter.

Most studies on innovation diffusion end with a discussion of its resultant adoption but do not look at outcomes of the adoption process. Until the 1960s, an underlying assumption of diffusion theory was that a new product or practice offered an indisputable benefit. Innovations were viewed as pure gains - a replacement of the outdated and inefficient with something better [10]. However, more recent research has drawn attention to negative social and environmental effects of innovations. Additionally, new technologies may not always result in expected improvements in outcomes such as yields. Given the poor potato yields in Kenya, we sought to establish whether the adoption of a package of the well-established innovation inputs would lead to significant improvements in yields. To this end we examined the extent and drivers of adoption rates and analyzed their impacts on yields.

\section{Methods}

A survey was conducted in 2010 and the first quarter of 2011 in three counties of Nakuru (Njoro and Kuresoi), Nyandarua (Nyandarua South, Nyandarua West and Nyandarua Central) and Meru (Meru Central and Buuri). The three counties are located in in the Rift Valley, Central and Eastern regions of Kenya, respectively. Central region is the leading producer of potatoes in Kenya followed by Rift Valley and Eastern Region. The study counties are the main potato growing areas in their respective regions and together account for approximately 95\% of total potato production in Kenya [11].

The areas studied are all in high altitude- (between 1,400 and 2,700 meters above sea level) and high-rainfall zones, experiencing mean annual rainfalls of $1,000 \mathrm{~mm}$ or greater. Nyandarua County has temperatures ranging from a minimum of $2^{\circ} \mathrm{C}$ to a maximum of $25^{\circ} \mathrm{C}$. The rainfall ranges between 700 and $1,500 \mathrm{~mm}$ per annum [12]. In Meru County, annual temperatures range from a minimum of $16^{\circ} \mathrm{C}$ to a maximum of $23^{\circ} \mathrm{C}$ and rainfall from 500 to 2,600 mm. Temperatures in Nakuru County range from a minimum of $12^{\circ} \mathrm{C}$ to a maximum of $26^{\circ} \mathrm{C}$ per year with rainfall ranging from 1,800 to $2,000 \mathrm{~mm}$. Maximum temperatures across all study counties, therefore, are sufficiently temperate, as are minimum temperatures - with the exception of Nyandaura. The highest variability in rainfall is recorded in Meru, where some areas receive less than $1,000 \mathrm{~mm}$ per year, which may explain the high usage of irrigation in the county. The predominant soil type is volcanic in Nyandarua and Meru but some parts of Nyandarua have red clay soil. Nakuru mainly has loamy soils.

Since no complete household survey has been carried out in in the last 5 years, we used data from the Kenya Integrated Household Budget Survey (KIHBS) 2005/ 2006 [13] to estimate the number of households producing potatoes. The total number of such households was 790,752, of which virtually all (97\%) were located in the main Central, Rift Valley and Eastern producingregions.

KIHBS data also provided estimates of the share of potato-growing households in each target county. In Nyandarua, $97 \%$ of farmers grew potatoes compared to $34 \%$ in Nakuru and 31\% in Meru. Together, the three counties accounted for about 33\% of all potato growing households in Kenya.

Relevant KIHBS data is aggregated at the level of households. Equally, the respondents targeted in our study were the heads of households. Interviews captured the demographic characteristics of the household head. The household is defined as a place where members 'eat from the same pot'. In the regions studied, this was also synonymous with housing units since independent households in these rural areas do not share the same house.

To be able to generate a random sample from the three regions, we used administrative district-level information gathered through a 2009/2010 enumeration of potato farmers by the Ministry of Agriculture. For some parts of Nakuru (Njoro and Kuresoi), data were incomplete, requiring us to employ a stage-wise stratified sampling approach, estimating the number of farmers in a village and selecting one at a constant interval.

The required sample size (n) was 381 as per the formula below. We however, targeted 419 farmers, assuming a 10\% non-response rate and ended up with 402 completed questionnaires.

Formula:

$$
\mathrm{n}=\frac{\mathrm{t}^{2} \times \mathrm{p}(1-\mathrm{p})}{\mathrm{m}^{2}}
$$


Description:

$\mathbf{n}=$ required sample size

$\mathbf{t}=$ confidence level at 95\% (standard value of 1.96)

$\mathbf{p}=$ estimated proportion of farmers growing potatoes used 55\% average as per occurrence in KIHBS [8]

$\mathbf{m}=$ margin of error at $5 \%$ (standard value of 0.05 )

Using the KIHBS [8] data for the farmers involved in potato production, the average occurrence was $54 \%$ as below:

$$
\begin{array}{rl}
0.97 & * 104637 / 264729+0.31 * 40660 / 264729+0.34 \\
& * 90381 / 264729=54.7 \%
\end{array}
$$

Calculation:

$$
\begin{aligned}
& \mathrm{n}=\frac{1.96^{2} \times .55(1-0.55)}{0.05^{2}} \\
& \mathrm{n}=\frac{3.8416 \times 0.2475}{0.0025} \\
& \mathrm{n}=\frac{0.9508}{0.0025} \\
& \mathrm{n}=380.32 \text { Approximately } 381
\end{aligned}
$$

The survey questionnaire was designed to collect data that could be used to generate additional variables. To increase the reliability of self-reported data, the questions asked were simple and information sought easy to recall. For instance, on yields, farmers were asked about the portion of their land they had dedicated to potatoes in the last season and the production thereof. Total production was divided by the area to generate yield data. Since the study sought to examine production in general, data on the varieties grown were not collected. The specific fertilizers and fungicides used were recorded but the ranges of fungicides were too wide to be analysed meaningfully. Several types of fertilizers were reportedly used but most farmers were unable to recall the specific kind used. As they put it, they simply follow sellers' advice on the type to purchase. The analysis, therefore, ignores fertilizer distinctions. For irrigation, the data collected were on installed irrigation facilities as opposed to actual use. It was assumed that those who had installed facilities actually used them.

The analysis used the Chi-square and Fisher's test, regression and logistic regression, where the dependent variable was dichotomous. Stata/SE 10.1 was used for the analysis.

\section{Study results and discussions}

The study found clean seeds, fungicides and fertilizers to be the most important production inputs that could easily be identified by the farmers and impacted on yields. Irrigation, the other key innovation was captured alongside other household characteristics as opposed to a farm input.
We used logistic regression to investigate the relationship between household characteristics, communication variables and adoption of the three focal input innovations. Table 2 presents results of estimating the probability of adopting the three innovations. The Chi-square statistic indicates strong significance $(P<0.01)$ of two of the models (seeds and fertilizer) over the simple model that includes only a constant. The goodness of fit for each of the models can be assessed through the pseudo $R$-square measure, which in our models ranges from 7.2 to $20.2 \%$. Our models thus have good predictive ability for adoption. We will look at each of the adoption outcomes separately.

We conducted both linear and nonlinear regression analyses to determine the contribution of farm inputs to yields. In both cases, we controlled for household characteristics and communication variables. A step-wise regression process was introduced given a very low $R$ squared value in the linear regression. This led us to a nonlinear equation for regression analysis.

\section{Adoption of clean seeds}

A very high proportion of farmers $(79 \%)$ are aware that they should use clean seeds but only $4.48 \%$ actually did so. This figure, moreover, is likely to be higher than in other less dominant potato growing areas. In the study, we only considered seeds bought from certified seed producers as clean. The price of clean seeds is more than double that of recycled uncertified seeds and readily obtainable. Our estimation based on data from the Kenya Plant Health Inspectorate Services [11], the sole certifier of seeds in Kenya, indicates that available stocks of certified seeds are only about $2 \%$ of the country's seed potato requirements. FAO estimates for 2009 put the acreage on which potatoes are grown in Kenya at 120,246 ha, suggesting a seed requirement of $240,492,000 \mathrm{~kg}(120,246 \times 2,000)$. Kenya Plant Health Inspectorate Services (KEPHIS) data, therefore, indicates that the certified seeds quantities were only $0.21 \%$ of the seed potato requirements in 2009 (Table 3). Assuming that certified seeds are multiplied at least once to give clean but not certified seeds, that is, presuming a multiplication ratio of 1:10, we estimate that clean seeds available to farmers in 2009 may only have ended up meeting $2.1 \%$ of the seed potato requirement. With such a low percentage of supply in the market, the odds are that many farmers who may wish to adopt clean seeds have not been able to do so.

As mentioned above, existing research suggests that the younger the head of household, the better the education and the larger the farm, the more likely is a household's adoption of an innovation [7,8]. Though Obare et al. [15] had contrary findings that education has no effect on adoption, our results indicated no statistically significant relationship between the level of education 
Table 2 Descriptive statistics for the full dataset

\begin{tabular}{|c|c|c|c|c|}
\hline Variable & Mean value/percent & SD & Min & Max \\
\hline Adoption of clean seeds & 0.0447761 & 0.20707 & 0 & 1 \\
\hline Proper fertilizer use & 0.181592 & 0.385988 & 0 & 1 \\
\hline Use of fungicides & 0.9179104 & 0.274843 & 0 & 1 \\
\hline Age (young = less than $40 \mathrm{yrs}$, old = above $40 \mathrm{yrs}$ ) & 0.2835821 & 0.451298 & 0 & 1 \\
\hline Gender (18.41\% female) & 0.1840796 & 0.388032 & 0 & 1 \\
\hline Education (None \& Primary =0, Secondary, Post-secondary=1) & 0.4825871 & 0.500319 & 0 & 1 \\
\hline Size of land & 4.457916 & 5.873537 & 0 & 60 \\
\hline Employment status (Employeed=1) & 0.0895522 & 0.285895 & 0 & 1 \\
\hline Irrigation & 0.2338308 & 0.423793 & 0 & 1 \\
\hline Number of cows & 2.375622 & 2.413739 & 0 & 20 \\
\hline Region (Eastern=1) & 0.2985075 & 0.458174 & 0 & 1 \\
\hline Visited (Visited=1) & 0.5472637 & 0.498381 & 0 & 1 \\
\hline Ownership of media equipment & 0.920398 & 0.271013 & 0 & 1 \\
\hline Member of farmers group & 0.3109453 & 0.463457 & 0 & 1 \\
\hline
\end{tabular}

and the adoption of clean seeds, In contrast, land size and number of cows owned by the household head, indicated no significant results. Having been visited by propagation agents, had a significant positive association with adoption, the latter pointing to the importance of communication about clean seeds. The gender, age, employment status, use of irrigation and region of residence of the household head did not significantly predict adoption.

Some contextual considerations can help in interpreting these findings. Land is in many cases a sign of wealth, as is the number of cows owned. Given the high cost of clean seeds, it would have been expected that higher adoption would be found among those with more land and cows is not surprising and, indeed, is to be expected. Similarly, the scarcity of seeds likely renders efforts to procure them more worthwhile for farmers who will use them on a larger area. Clean seeds are not distributed but instead have to be sourced directly from the producers. Because procurement in most cases involves transportation, there are economies of scale when procuring for a bigger farm. The number of cows owned by a potato farmer (typically used for dairy production)

Table 3 Seed potatoes certified by Kenya Plant Health Inspectorate Services (KEPHIS) in kilograms

\begin{tabular}{cc}
\hline Year & Quantity in kg \\
\hline 2005 & $64,800.00$ \\
2006 & $418,300.00$ \\
2007 & $230,600.00$ \\
2008 & $369,091.00$ \\
2009 & $496,100.00$ \\
\hline
\end{tabular}

Source: KEPHIS [14]. is an important determinant of the income available to be invested in purchasing expensive seeds. However, only education and visits by innovation propagation agents influenced adoption meaning that failure to adopt clean seeds can largely be as a result of lack of knowledge. Visits by innovation propagation agents influenced the level of awareness of clean seeds - a prerequisite for their adoption. Taken together our findings suggest that although there is high awareness on the existence of clean seeds, it takes a higher level of education to appreciate the need to navigate the highly inefficient clean seeds supply chain. Interviews with seed producers indicated that in addition to a highly insufficient quantity of clean seeds in Kenya, the few existing seed multipliers lack effective marketing and distribution systems. As a result, farmers have to incur transport costs to collect seeds. The experience of one of the authors illustrates the long distances and attendant costs that can be involved: to obtain a large enough quantity of seeds for a field experiment, trips to two seed producers located more than $200 \mathrm{~km}$ apart were necessary. In addition to incurring transport costs, farmers pay high prices for certified seeds, which cost on average Ksh 2,000 per $50-\mathrm{kg}$ bag compared to less than Ksh 1,000 for recycled or unclean seeds. Unless one fully appreciates the benefits of clean seeds, he or she is unlikely to take the trouble to source them.

\section{Fertilizer usage}

The proportion of farmers using fertilizer in the potato growing areas is higher than the national average of $69 \%$ [13]. Potatoes respond better to chemical fertilizers than do other crops that thrive with animal manure. Use of animal manure, which may be contaminated with bacteria 
wilt, carries the risk of serious disease for potato plants. Farmers are, therefore, discouraged from using animal manure unless they are sure it is clean. A large majority of interviewed farmers (96\%), therefore, reported using fertilizers. This raises a key question as to how their usage compares to recommended practice.

We asked each farmer about the size of land on which they grew potatoes and the amount of fertilizer they used. Using a standard recommended rate of four $50-\mathrm{kg}$ bags per acre, we were able to examine the extent of adoption of fertilizers. Our findings show that only $18 \%$ of those using fertilizers are using the required quantities, $72 \%$ use less than the requirement and $8 \%$ use excess quantities. The under-use of fertilizer is certain to affect yields, given that the land on which potatoes are grown is typically over farmed - making fertilizer-use paramount for obtaining good harvests. It would appear that the recommended quantity of fertilizer per area is not commonly known.

Among the characteristics of the household head, only-ownership of irrigation equipment and the region the farmer come from were found to have a significant relationship with fertilizer usage. Age, education level, employment status and size of land were found to be insignificant. Irrigation is mainly applied in only one of the regions studied. The fact that proper usage of fertilizer is associated with irrigation use and the region of residence from indicates that proper usage is more prevalent among commercial farmers. These are farmers who are investing more on farming including the use of irrigation equipment. They therefore go an extra mile to ensure that they use the appropriate quantity of fertilizer in order to obtain optimum yields.

Among the communication variables only membership of farmer group was significant predictors of correct fertilizer use. It was surprising that visits by innovation propagation agents did not influence proper usage of fertilizer. Those who have been visited by innovation propagation agents in the last three years are more likely to apply the right quantity of fertilizer (24.54\% compared to $10.44 \%$ for those not visited). The visits are highest in Eastern Region (73\%), second highest in Central Region (61\%) and lowest in the Rift Valley Region at 30\%. This difference arises from the region of residence which emerged as a significant factor for proper application of fertilizers. The Ministry of Agriculture was identified as the leading innovation propagation agent that had visited farmers in the last three years, accounting for $80 \%$ of total visits. Though about half (55\%) of the farmers were visited, the visits were very high in the Eastern region at $73 \%$ as compared to $61 \%$ for Central and $30 \%$ for the Rift Valley region. The Ministry of Agriculture has a strategy of only seeing farmers who are involved in particular projects or specifically requests a visit.
There are significantly better results for fertilizer usage for those who also use clean seeds (Table 4). The high cost of clean seeds may encourage efforts to properly apply fertilizer in order to ensure that investment in such seeds is properly recovered through good yields.

\section{Use of fungicides}

Besides bacteria wilt, another serious disease for potatoes in the tropics is late blight. The disease is controlled by spraying fungicides. Virtually all respondents (92\%) reported using fungicides. Computing the extent of usage was not possible, however, given the different brands in the market, the different application regimes and the fact that application is in most cases dependent on the weather conditions. We were therefore unable to work out the extent of usage.

A correct, early timing of the first fungicide application is as important as its extent for forestalling disease. However, clearly not all farmers are cognizant of this. Responses to the question 'what prompts first application of fungicides' included, 'after germination for control purposes', 'as a preventive measure', 'when symptoms of disease are identified', and 'when weather changes' (rain and cold temperatures). About a quarter of the farmers did not answer the question and some gave multiple answers. We therefore considered it inappropriate to analyze the quality of usage. We therefore focused only on application and non-application. The number of cows, size of land owned and the region of residence emerged as a significant predictors. The first two are proxies for wealth indicating that there is more adoption of fungicides by well to do farmers. The log likelihood was only significant at $10 \%$.

Fungicide manufacturers and retailers in Kenya engage in aggressive marketing and distribution, among some including through use of dedicated field officers to work with farmers. This likely explains the many different brands being used and the high level of uptake. Knowledge of fungicides is well-spread in the farming communities. Semi-structured interviews with the farmers revealed that most of them routinely shop for fungicides. Their application regime, however, appears to be rather haphazard.

Clean seeds, fertilizer use, fungicides, irrigation and yields As a next step in the analysis we introduced irrigation into a regression model comprising all key variables, with a view to investigating their impacts on yields. Though irrigation has mainly been considered a household characteristic, experiences of other potato-producing countries, like South Africa and Egypt, suggest that it is an important determinant of productivity. South Africa and Egypt have average yields of 33 and 25 tons per hectare respectively, with 75 and $100 \%$ of the crop, respectively, grown under 
Table 4 Adoption of clean seeds, proper use of fertilizers and use of fungicides

\begin{tabular}{|c|c|c|c|c|c|c|c|c|}
\hline \multirow[b]{2}{*}{ Variable } & \multicolumn{3}{|c|}{ Seeds } & \multicolumn{3}{|c|}{ Fertilizer } & \multicolumn{2}{|c|}{ Fungicides } \\
\hline & Coefficient & Robust SE & $P$ & Coefficient & Robust SE & $P$ & Coefficient & Robust SE \\
\hline Age & -1.480892 & 1.045255 & 0.157 & -0.3782178 & 0.3851948 & 0.326 & -0.1278965 & 0.4698768 \\
\hline Gender & -0.321191 & 0.7842926 & 0.682 & -0.1184211 & 0.4007041 & 0.768 & -0.4856607 & 0.4495826 \\
\hline Education & 0.9821727 & 0.5520274 & $0.075^{*}$ & 0.2845236 & 0.3259048 & 0.383 & 0.4638435 & 0.3788872 \\
\hline Size of land & 0.0258104 & 0.0465198 & 0.579 & -0.0391673 & 0.0398019 & 0.325 & -0.0846073 & 0.0458748 \\
\hline Employment status & 0.0255295 & 0.8811416 & 0.977 & 0.8092282 & 0.5437259 & 0.137 & -0.0704882 & 0.8370973 \\
\hline Irrigation & 0.4484032 & 0.799934 & 0.575 & -1.18545 & 0.392375 & $0.003^{* *}$ & 0.4234932 & 0.5356169 \\
\hline Number of cows & 0.1624452 & 0.1127645 & 0.15 & 0.016982 & 0.0854269 & 0.842 & 0.2514047 & 0.1170051 \\
\hline Region & -0.2813659 & 0.8075803 & 0.728 & 2.297463 & 0.3866888 & $0^{* * *}$ & -1.164979 & 0.5331393 \\
\hline Visited & 1.692598 & 0.6676563 & $0.011^{* *}$ & 0.4122967 & 0.3488554 & 0.237 & 0.343017 & 0.4321116 \\
\hline Ownership of media equipment & -0.8326009 & 0.8493516 & 0.327 & 0.6678926 & 0.8132582 & 0.412 & 0.193444 & 0.6770312 \\
\hline Member of farmers group & 0.242039 & 0.5296039 & 0.648 & 0.7640476 & 0.3192164 & $0.017^{* *}$ & 0.2863781 & 0.5342112 \\
\hline Use clean seeds & & & & 1.280824 & 0.5803187 & $0.027^{* *}$ & -0.1089398 & 1.212624 \\
\hline Proper fertilizer use & 1.293441 & 0.6205842 & $0.033^{* *}$ & & & & 0.6277023 & 0.7238252 \\
\hline Use fungicides & 0.2355052 & 1.908216 & 0.879 & 0.5306858 & 0.7029454 & 0.45 & & \\
\hline Constant & -5.995303 & 3.703948 & 0.036 & -3.941271 & 1.307758 & 0.003 & 2.065371 & 0.761221 \\
\hline Log likelihood & -56.639018 & & $0.0 * * *$ & -143.30835 & & $0.0^{* * *}$ & -97.736995 & \\
\hline Chi-square statistic & 50.79 & & & 63 & & & 18.55 & \\
\hline Pseudo- $R 2$ & 0.2179 & & & 0.2097 & & & $0.068^{*}$ & \\
\hline Number & 379 & & & 379 & & & 379 & \\
\hline
\end{tabular}

Results as presented are for estimation of the probability of adopting the three innovations. ${ }^{*} P<0.1,{ }^{* *} P<0.05,{ }^{* * *} P<0.01$ (two tailed test).

irrigation $[16,17]$. The regions studied in this research had an irrigation rate of 4, 59 and 13\% for Central, Eastern and Rift Valley, respectively, with an overall average of $23 \%$.

Our findings presented in Table 5 show an average yield of 14.48 tons per hectare for those using fertilizers in the right proportion as compared to 11.68 tons per hectare for those using lower than the recommended quantity of fertilizer. Farming households using in excess of the recommended quantity produce only marginally more (12.91) than those using less than the suggested amount. Those using clean seeds have an average yield of 15.75 tons per hectare as compared to 12.00 tons per hectare for those not using clean seeds. There is less variation in yields for those who use fungicides and those who do not, with 12.42 and 9.45 tons per hectare, respectively. Similarly, households applying irrigation had an average yield of 13.81 as compared to 11.66 tons per hectare for those without irrigation facility. Those both using clean seeds and applying the appropriate quantity of fertilizer were obtaining an average yield of 18.35 tons per hectare as compared to 16.39 tons per hectare for households combining the use of clean seeds and fungicides. The overall average yields for the whole sample studied was 12.17 tons per hectare. The apparent differential impact of innovations is underscored in Table 6, which shows linear and nonlinear regression results for clean seeds, proper fertilizer use, use of fungicides and irrigation as independent variables and yield as the dependent variable. The results show a considerably higher coefficient for clean seeds than for fungicides or fertilizers, suggesting a greater impact of clean seeds on enhancing yields. Regressing the three variables on yields (seeds, fertilizer and fungicides), a low $R^{2}$ value of $5 \%$ was obtained, which only rose to $12.3 \%$ when introducing socioeconomic characteristics ${ }^{\mathrm{a}}$ to the model. The low $\mathrm{R}^{2}$ value may be attributable to nonlinearity where a number of factors contribute to random or unpredictable behavior. Instances of heteroskedasticity or even non-normality may also be contributing factors. We therefore tested whether or not linear regression assumptions were violated by examining the residuals for normality. The SmirnovKolmogorov test gave a probability of less than 0.05 indicating that the residuals are non-normally distributed. However, the values of the standardized residuals did not exceed 3.5 or fall below -3.5 suggesting that there were no outliers. We used the Cook-Weisberg test to check for heteroscedasticity. We obtained an insignificant result, indicating lack of heteroscedasticity or homoscedasticity (presence of equal variance of the residuals along the predicted line). We tested for multi-co-linearity but obtained variance inflation factors of less than 5 , indicating that the multiple models did not include two or more highly correlated predictor variables.

The histogram of the independent variable (yield) indicates that it is not normally distributed. Statistical and 
Table 5 Fertilizer use per acre, clean seeds, irrigation and average yields

\begin{tabular}{|c|c|c|c|c|}
\hline & Average yield (Tons/Ha) & SD & Min & Max \\
\hline \multicolumn{5}{|l|}{ Fertilizer use } \\
\hline Proper use & 14.47705 & 5.640542 & 2.7181 & 25.00652 \\
\hline Underuse & 11.68091 & 6.224888 & 1.019287 & 33.16082 \\
\hline Overuse & 12.91097 & 6.671999 & 2.17448 & 26.09376 \\
\hline \multicolumn{5}{|l|}{ Seeds } \\
\hline Clean seeds & 15.74899 & 4.371697 & 5.4362 & 21.7448 \\
\hline Non-clean seeds & 12.00645 & 6.340899 & 0.81543 & 33.16082 \\
\hline \multicolumn{5}{|l|}{ Fungicides } \\
\hline Use fungicides & 12.41601 & 6.268137 & 0.81543 & 33.16082 \\
\hline Do not use & 9.454046 & 6.229853 & 2.71810 & 27.18100 \\
\hline \multicolumn{5}{|l|}{ Irrigation } \\
\hline Has irrigation & 13.81068 & 5.936193 & 1.08724 & 33.16082 \\
\hline Does not have irrigation & 11.66037 & 6.345868 & 0.81543 & 28.26824 \\
\hline \multicolumn{5}{|l|}{ Combined } \\
\hline Clean seeds and proper fertilizers & 18.34717 & 2.639298 & 13.04688 & 21.74480 \\
\hline Clean seeds and fungicides & 16.39354 & 3.58500 & 9.78516 & 21.74480 \\
\hline Proper fertilizers and fungicides & 14.57256 & 5.603104 & 2.71810 & 25.00652 \\
\hline Clean seeds and irrigation & 13.81068 & 5.936193 & 1.08724 & 33.16082 \\
\hline Clean seeds, proper fertilizers and fungicides, irrigation & 18.34717 & 1.545576 & 16.03679 & 19.29851 \\
\hline Overall (general) & 12.16793 & 6.310752 & 0.81543 & 33.16082 \\
\hline
\end{tabular}

graphical tests on Stata software indicate nonlinearity for fertilizer use per acre and yields. Yields increase with additional fertilizer application up to a certain point after which they decrease. The graph of yields on fertilizer approximates a parabola with a vertex points (279.50, 14.15) representing the highest point for which fertilizer usage per acre gives the highest yield on the fitted curve. The function can be expressed as:

$$
\mathrm{Y}=0.0402097 * \mathrm{~F}-0.0000678 * \mathrm{~F} * \mathrm{~F}
$$

Where $\mathrm{F}$ is the fertilizer use per acre. The peak for the $\mathrm{x}$ axis is 279.5, which is the optimal quantity of fertilizer recommended. The peak the y axis is 14.15 tons per hectare (Figure 1).

We then conducted a nonlinear regression analysis of yields on the four independent variables, where b1, b2, b3 and b4 are the coefficients for the independent variables, as follows:

$$
\begin{aligned}
n l(\text { yield }= & (\text { bo }+\{b 1\} *(\text { fertuseacre } \\
& + \text { b2 fertuseacre } * \text { feruseacre }) \\
& +\{b 3\} * \text { seed }_{\text {clean }}+\{b 4\} * \text { usefungicides. }
\end{aligned}
$$

The coefficients in the nonlinear regression still show that clean seeds have the highest impact (also in Table 6). Removing the linearity assumption improves the $R^{2}$ value to $8.54 \%$ leaving a whole 93\% unexplained variance. The inclusion of social economic characteristics in the regression equation above improves $R^{2}$ value to $13.82 \%$. We speculate that the unexplained variance could be due to other ecological factors in the value chain that have not been incorporated in the regression model. These include a high micro-variability in land quality - that is a relative instability of soils and their different responses to application of inputs [18], as well as soil conditions prior to use of clean seeds, fertilizer, or fungicides. Soils that already contain bacteria wilt will limit yields even when all required inputs are used correctly. Overmined soil may require additional organic materials besides fertilizers to obtain optimum results for a fertilizer. Climate variations are also important, given that potato diseases such as late blight are made worse by temperatures variations. These other factors not included in the model may explain the large confidence intervals reported in the model.

\section{Conclusions}

Determinants of innovation adoption

In the three models of clean seeds, proper fertilizer use and use of fungicides, age, size of land, education level, number of cows, region, visits of innovation agents, possession of irrigation equipment and membership of farmers' groups are shown to have a significant positive association with 
Table 6 Nonlinear and linear regression on yields

\begin{tabular}{|c|c|c|c|c|}
\hline \multirow[b]{2}{*}{ Yield } & \multicolumn{2}{|c|}{ Linear regression } & \multicolumn{2}{|c|}{ Nonlinear regression } \\
\hline & Coefficient & $P$ value & Coefficient & $P$ Value \\
\hline Fertilizer use per acre & 0.01168 & $0.001^{* *}$ & 0.0362579 & $0.00^{* * *}$ \\
\hline Fertilizer use per acre squared & & & -0.0000605 & $0.001^{* * *}$ \\
\hline Clean seeds & 3.11066 & $0.041^{*}$ & 2.450674 & 0.109 \\
\hline Use fungicides & 1.84136 & 0.138 & 2.322216 & $0.037^{* *}$ \\
\hline Constant & 9.06671 & 0 & 7.172435 & $* * *$ \\
\hline \multirow[t]{3}{*}{$R^{2}$} & 4.78 & & 8.54 & \\
\hline & \multicolumn{4}{|c|}{ Controlling for social-economic characteristics } \\
\hline & \multicolumn{2}{|c|}{ Linear regression } & \multicolumn{2}{|c|}{ Nonlinear regression } \\
\hline Yield & Coefficient & $P$ Value & Coefficient & $P$ Value \\
\hline Fertilizer use per acre squared & & & -0.0000483 & $0.009^{* *}$ \\
\hline Fertuse per acre & 0.0070554 & $0.056^{*}$ & 0.0273886 & $0.001^{* * *}$ \\
\hline Use clean seeds & 2.190173 & 0.165 & 1.805383 & 0.25 \\
\hline Use fungicides & 2.667031 & $0.018^{* *}$ & 2.352725 & $0.037^{*}$ \\
\hline Has irrigation equipment & 0.5149959 & 0.56 & 0.6793034 & 0.44 \\
\hline Size of land owned & 0.0548732 & 0.427 & 0.0420069 & 0.541 \\
\hline Education - Secondary Sch. \& above & 0.3303141 & 0.624 & 0.387795 & 0.563 \\
\hline Gender (Female) & -1.812674 & $0.027^{* *}$ & -1.794205 & $0.027^{* *}$ \\
\hline Not employed & -0.3628529 & 0.751 & -0.1604294 & 0.888 \\
\hline Retired & -1.093352 & 0.415 & -1.040537 & 0.434 \\
\hline Age ( $40-49$ years) & -1.060726 & 0.225 & -1.005677 & 0.246 \\
\hline Age (50-59 years) & 0.1877138 & 0.833 & 0.4085131 & 0.646 \\
\hline Age (Above 60 years) & -1.264216 & 0.204 & -0.9387634 & 0.345 \\
\hline Region - Central & -2.018409 & $0.033^{* *}$ & -1.752407 & $0.064^{*}$ \\
\hline Region - Rift Valley & -2.733439 & $0.006^{* *}$ & -2.257026 & $0.025^{* *}$ \\
\hline Visited by Agr. Officer & 0.4646729 & 0.507 & 0.2337566 & 0.738 \\
\hline Own Radio or TV & -1.090301 & 0.365 & -1.092433 & 0.36 \\
\hline Member of farmer group & 0.1880047 & 0.794 & 0.1577523 & 0.826 \\
\hline Number of cows & 0.0860794 & 0.601 & 0.0973959 & 0.551 \\
\hline Constant & 11.76595 & $0.000^{* * *}$ & 10.34928 & $0.000^{* * *}$ \\
\hline$R$ squared & 12.3 & & 13.82 & \\
\hline
\end{tabular}

${ }^{*} P<0.1,{ }^{* *} P<0.05,{ }^{* * *} P<0.01$.

adoption in at least one model, with the region of residence being significant in two models (Table 4).

Usage of clean seeds is influenced by awareness levels as indicated by the education level (secondary school and above) and visits by innovation propagation agents. The low supply of clean seeds and the complex procurement issues make only those who fully appreciate the impact of using clean adopt them. Proper fertilizer usage is evident in the region that have also adopted irrigation indicating commercialization of agriculture including the usage of irrigation is a stronger factor in the usage of appropriate quantities of fertilizers. Use of fungicides appears to be influenced by wealth levels as represented by the size of land and the number of cows that a farmer has. The region of residence which is also significant for use of fungicides could also be pointing to the different levels of wealth in the three regions studied.

The importance of communication variables is clearly shown in the case of usage of clean seeds. Visits by innovation propagation agents were significantly associated with the use of clean seeds. Communication variables influence adoption and when lacking in supply they constrain adoption. Visits by innovation propagation agents positively influenced the adoption of clean seeds and proper usage of fertilizers. The Ministry of Agriculture may need to review its visits strategy to accommodate routine visits to farmers at least once a year. This used to be the practice in the 1970s but was abandoned due to resource constraints. 


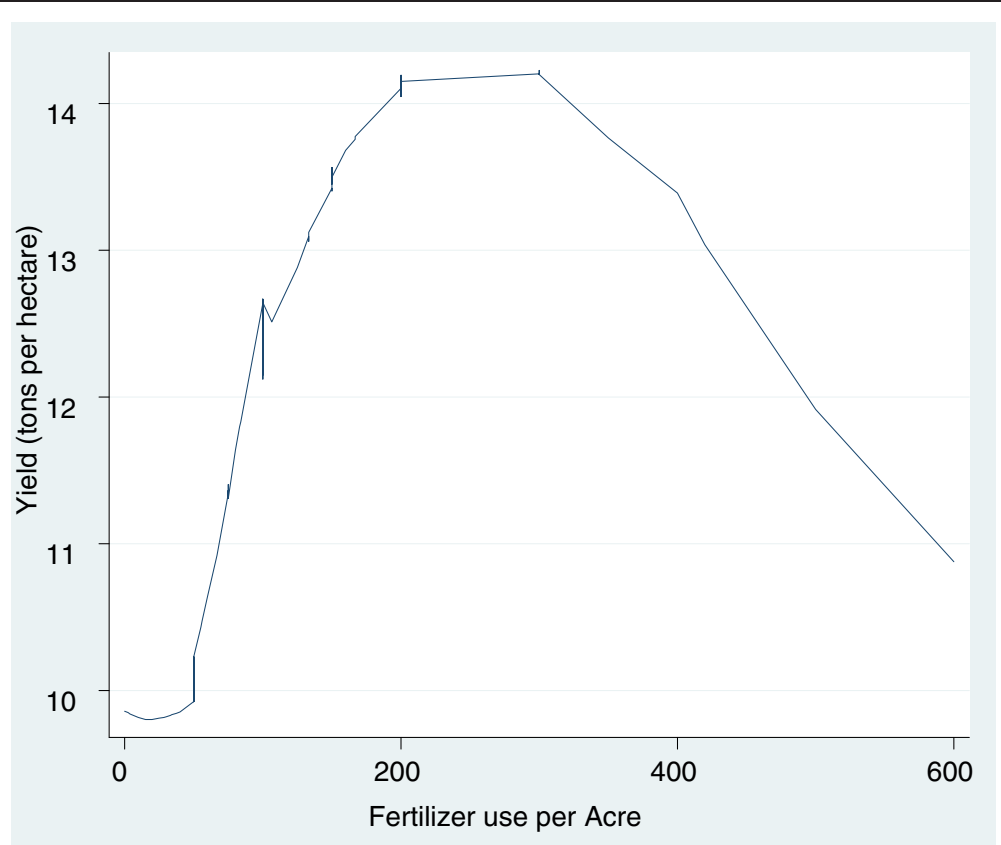

Figure $1 \mathrm{Graph}$ on yields and fertilizer use.

More investments in agriculture to allow increased visits to farmers, combined with strategies to successfully and systematically convey information on 'best' agronomic practices to farming communities may help enhance the currently poor performance of potatoes in Kenya. Issues like improper use of fertilizer could likely be resolved to a great extent if farmers were adequately trained.

\section{Adoption of innovations and yields}

The adoption of clean seeds, proper usage of fertilizers, fungicides and irrigation enhances potato yields, with clean seed use giving the greatest enhancement. The existence of nonlinear relationships suggests that precision in fertilizer usage is critical since there is an optimum application point. This further underscores a need for effective training or raising awareness among potato farmers about key recommended practices for optimum yields of their crop. Given the importance of precision, the low average potato yields in the study area, reaching a maximum of 18.35 tons are unsurprising. To achieve harvests of up to 40 tons per hectare as in some developed regions, more precise application is required. Additionally, Innovations such as soil testing to determine the input requirements will help determine the appropriate application regime. Better control of adverse factors like bacteria wilt, which manifest when clean seeds are used on diseased farms, would also contribute to enhancing yields. Other factors may be uncontrollable, such as climate.

Though a wider adoption of clean seeds, proper usage of fertilizers, fungicides and irrigation as they are applied currently is unlikely to contribute to drastic improvements in potato yields for Kenya, it is still a worthwhile goal to pursue, as the present low national outputs do not do justice to the huge tracts of land devoted to the crop. An adoption of these key inputs by a higher percentage of farmers could lead to more than a doubling of Kenya's output. If this is done alongside a promotion of more potato consumption, Kenya would reduce its maize imports and enhance its food security.

\section{Endnote}

${ }^{a}$ Social economic characteristics used were education, employment status, gender, region, whether visited by agricultural officials, possession of radio, whether they keep records, distance from a paved road and whether a member of a farmer's group.

\section{Abbreviations}

FAO: Food and Agriculture Organization; HYV: High yielding varieties; KEPHIS: Kenya plant health inspectorate services; KIHBS: Kenya integrated household budget survey.

\section{Competing interests}

Both authors declare that they have no competing interests.

\section{Authors' contributions}

JGW carried out the field work and did the analysis. Professor MPVD was involved in the design of the study and supervised the work, which is part of a Doctorate of Business Administration at Maastricht School of Management, Netherlands. Both authors read and approved the final manuscript.

\section{Authors' information}

JGW is a doctoral candidate at Maastricht School of Management, Netherlands. He works with the African Population and Health Research Center where he holds the position of Director of Operations. MPVP is JGW's supervisor at Maastricht School of Management (MSM). Besides being a professor at MSM, he is a Professor of Water Services Management at the UNESCO-IHE Institute for Water Education. 


\section{Acknowledgements}

We acknowledge the immense help we obtained from the Ministry of Agriculture officials both at the head office and the counties studied in the sampling and collection of data. We also acknowledge the Round Table Africa program of the Maastricht School of Management that funded part of the study. We also acknowledge Mr Maurice Mutisya, Dr Moses Oketch and Dr Djesika Amendah, all of the African Population and Health Research Center for support in data analysis. We thank Dr Isabella Aboderin' for painstakingly editing the paper.

\section{Author details}

${ }^{1}$ Maastricht School of Management, Maastricht, Netherlands. ${ }^{2}$ African Population \& Health Research Center, P.O. Box 10787, Nairobi 00100, Kenya.

${ }^{3}$ UNESCO-IHE Institute for Water education, Delft, Netherlands.

Received: 9 December 2012 Accepted: 19 September 2013

Published: 8 October 2013

\section{References}

1. FAO: FAO Statistics Division. 2011.

2. FAO: FAO Statistics Division. 2009. http://faostat.fao.org/site/567/default. aspx\#ancor, accessed in April 2012, November 2012, and April 2013.

3. FAO: FAO Statistics Division. 2012. http://faostat.fao.org/site/567/default. aspx\#ancor, accessed in April 2012, November 2012, and April 2013.

4. Quin NN: The potato contribution to population and urbanization: evidence from a historic experiment. O J Econ 2011, 126(2):593-650.

5. Van der Zaag D, Horton D: Potato production and utilization in world perspective with special reference to the tropics and sub-tropics. Eur Assoc Potato Res 1983, 26(4):323-362.

6. Brown L: Innovation Diffusion: A New Perspective. New York: Methuen \& Company, NY; 1981. 1(X)17.

7. Rogers E: Diffusion of Innovations. 5th edition. New York: The Free Press; 2003.

8. Unwin T: Household characteristics and agrarian innovation adoption in North-West Portugal. Trans Institute British Geographers, New Series 1987, 12:131-146.

9. Ruttan V: The green revolution: seven generalizations. Int Dev Rev 1977, 19:16-23. December 1977.

10. Redmond W: Innovation, diffusion, and institutional change. J Econ Issues 2003, 37(3):665-679.

11. Ministry of Agriculture: Annual report for 2008. Nairobi, Kenya; 2008.

12. Counties Profiles. 2013. http://www.softkenya.com accessed April 2013.

13. Republic of Kenya: Kenya Integrated Household Budget Survey 2005/6. Central Bureau of Statistics. Nairobi, Kenya: Ministry of Planning and National Development; 2007.

14. KEPHIS: Data provided by the organization officers. Nairobi, Kenya; 2009. April 2012.

15. Obare G, Nyagaka D, Ngoyo W, Mwakubo S: Are Kenya farmers allocatively efficient? evidence from Irish Potato producers in Nyandarua North District. J Dev Agric Econ 2010, 2(3):078-085.

16. Black V: Hot Potato. GM Potatoes in South Africa, a critical analysis. South Africa: The African Center for Biosafety; 2008.

17. FAO: FAO Statistics Division. 2005. http://faostat.fao.org/site/567/default. aspx\#ancor, accessed in April 2012, November 2012, and April 2013

18. Matlon PJ, Spencer DS: Increasing food production in sub-Saharan Africa: environmental problems and inadequate technological solutions. Am J Agric Econ 1984, 66(5):671-676.

doi:10.1186/2048-7010-2-14

Cite this article as: Wang'ombe and van Dijk: Low potato yields in Kenya: do conventional input innovations account for the yields disparity? Agriculture \& Food Security 2013 2:14.

\section{Submit your next manuscript to BioMed Central and take full advantage of:}

- Convenient online submission

- Thorough peer review

- No space constraints or color figure charges

- Immediate publication on acceptance

- Inclusion in PubMed, CAS, Scopus and Google Scholar

- Research which is freely available for redistribution

Submit your manuscript at www.biomedcentral.com/submit
Biomed Central 